this number, $10,000,000$, or $50 \%$, have defective teeth.

From such data, we can reasonably infer that defective teeth in school children is a condition not peculiar to Boston alone, but is widespread throughout the whole country.

A further investigation was made of the reports from the various sections of Boston, comparing conditions found in children coming from the best residential districts with those coming from less favored sections, with reference to dental caries, with the following result:

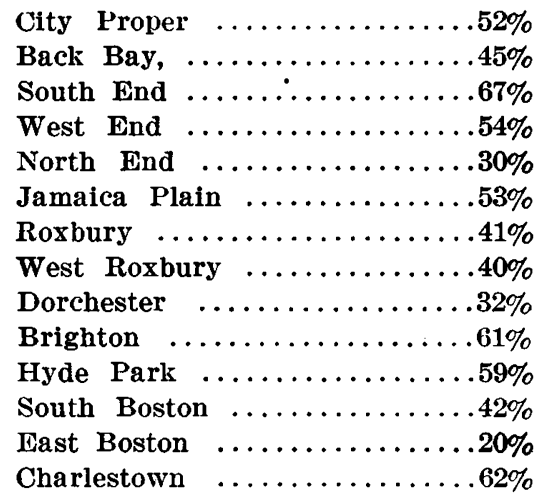

From the foregoing table we can also reasonably infer that dental caries is no respecter of persons, but attacks high and low with equal impunity.

In every instance, notice of the defective condition found was sent to the parent or guardian, informing him of the condition and recommending that treatment be sought, either at the hands of the family dentist or at some dental clinic.

Physical examinations for the year 1912-1913 are now under way and upon their completiun a complete list of the correction of defects can be furnished. Anticipating that such information in relation to dental caries might be sought at this meeting, a comparison of this year's examination with that of last year was made. We were able to make comparisons in 2,000 cuses. Statistics dealing with such small numbers may not be of much value, but it is encouraging to note that on the basis of 2,000 children reexamined, $70 \%$ were recorded without defects, as compared with $29 \%$ recorded without defects last year. Following down the list of corrections, we find that

\footnotetext{
Defective teeth corrected .....40\%

Hypertrophied tonsils .......42\%

Defective nasal breathing ......54\%

Cervical Glands ...........50\%
}

When we consider that dental charity in Boston, at present, is wholly inadequate compared with the opportunities for medical charity and when we consider that inquiry among dentists furnishes the information that Saturday is the only day on which they are able to make appointments with children, through the child's fear of marring school attendance record, we feel that this result is a tribute to parents who have demonstrated that they are able and willing to care for their children, once their attention is called to conditions which require treatment.

This widespread prevalency of dental caries among the children of all classes does not indicate any lack of parental instinct in caring for their young. It is simply due to ignorance of medical, dental and hygienic affairs about which no effort was made until the present time to provide information.

Sound teeth appeal to the average layman for their cosmetic value. That dental caries may be the harbor for all kinds of bacteria that some day may lay him low, probably has never caused him a thought. And yet, for some time, physicians have known that in the etiology of diphtheria, scarlet fever, pneumonia, tuberculosis, and other respiratory infections, dental caries play an important part. The educational value of this work then in calling attention to the train of evils which follow dental caries will be seen and felt in the prophylactic measures which will be applied to future generations.

Meanwhile, we are confronted with the problem of caring for defective teeth, as well as for other defects noted in the process of medical inspection of schools. As usual, when announcements of this nature are made extreme views are spread broadcast, perhaps from a desire to atone for a past of indifference and inactivity. In this category may be placed the suggestion to establish dental clinies in the school building. And if this position is tenable, clinies for the correction of other defects of equal importance as dental caries should follow. This line of suggestion followed to its logical conclusion leads to possibilities we dare not contemplate. From the earliest times, school has never been too attractive to the normal boy, and until it can be proven that parents have lost all sense of responsibility in caring for their offspring, the duty of the school physicians had better be confined to its present limits, i.e., to examine, refer and report.

\section{THE PURPOSE OF THE FORSYTH DEN-} TAL INFIRMARY.

BY TIMOTHY LEARY, M.D., BOSTON.

THE Forsyth Dental Infirmary for Children is a charity incorporated under the laws of Massachusetts whose purpose is to furnish to the worthy children of Greater Boston the dental care which they require.

Dr. William J. Gallivan in his report for the Division of Child Hygiene of the Boston Board of Health for 1911-1912 classifies the conditions found as a result of the physical examination of the Boston school children as follows: 
Number pupils examined . . . . . . . . . 118,781 Total number of pupils without defects ..... 40,850

Total number of pupils with defects .......77,931 Mental deficiency ......... 501

Defective nasal breathing ...... 9,693

Hypertrophied tonsils ......... 25,121

Defective teeth $\ldots \ldots \ldots \ldots \ldots \ldots 5,51,340$

Defective palate $\ldots \ldots \ldots \ldots \ldots, 371$

Cervical glands $\ldots \ldots \ldots \ldots \ldots \ldots 13,711$

100,236

PulmonaryDisease :

Pulmonary tuberculosis $\ldots \ldots \ldots \quad 133$

Acute bronchitis ........... 1,169

Asthma $\quad \ldots \ldots \ldots \ldots \ldots \ldots \ldots, 63$

Pleurisy $\ldots \ldots \ldots \ldots \ldots \ldots \ldots \ldots, \quad 42$

Miscellaneous $\ldots \ldots \ldots \ldots \ldots \ldots \ldots, \quad 987$

Cardiac disease ............. 3,091

Nervous disease $\ldots \ldots \ldots \ldots \ldots, \quad 505$

Orthopeciic defects:

Tuberculosis $\ldots \ldots \ldots \ldots \ldots \ldots, 693$

Non-Tuberculosis $\ldots \ldots \ldots \ldots, \quad 1,881$

Skin $\ldots \ldots \ldots \ldots \ldots \ldots \ldots \ldots, \mathbf{5 , 2 4 5}$

Rickets ................. 1,019

Malnutrition ............. $\mathbf{3 , 8 9 1}$

Total 119,456

It will be observed that defects were found in 68 per cent. of the children examined. The defects found total 119,456 , and of these the defects originating about the mouth and included under the headings: Defective Nasal Breathing, Hypertrophied Tonsils, Defective Teeth, Defective Palate, and Cervical Glands, total 100,236, or practically 84 per cent. of all defects found.

Most of the defective nasal breathing is due to adenoids (Dr. Gallivan's opinion), and recent work indicates that enlarged cervical glands are not, as has been thought, primarily tubercular, but are related to sources of infection in the mouth and subside promptly in most cases on cleaning up the mouth lesions.

These statisties do not include defects in the alignment of teeth with the exception of the most extreme deformities.

This then is the problem which the school children of Boston proper present at the present day from the standpoint of oral hygiene. The school population of suburbs of Boston within easy access of the city proper numbers about 110,000 , and it is a reasonable presumption that the percentage of defectives among these children should correspond to the findings in the Boston schools.

The solution of the dental portion of this problem lies in bringing the children under the care of experienced dentists. This might be done in one of two ways- (a) By causing the dentist to visit the children, or (b) By bringing the children to the dentist. The Trustees of the Forsyth Dental Infirmary for Children have given deep thought to this problem and have concluded that from all standpoints it was wiser and on the whole more practicable to bring the children to the dentist. This is the era of effort toward efficiency of human labor. The value of the time of a child is the cost of its education to the city which is estimated at 3 cents per hour. The element of time apparently lost to education can be ignored since it is being recognized that the physical well-being of the child is essential if it is to obtain full value from the instruction offered. Time apparently lost in obtaining dental care is, therefore, repaid many fold in the ultimate outcome.

The time of the dentist on the other hand can be estimated as worth from $\$ 3.00$ per hour upward. A fair estimate would fix it at about $\$ 5.00$ per hour. Unlike the physician who can make use of any part of the twenty-four hours in adding to his income, the dentist is limited to the daylight hours. With artificial light it is possible to lengthen the working day but at an expense to eyes and quality of work which leads the average dentist to confine his professional labors to an eight-hour day.

The physical effort of standing by an operating chair and carrying out manipulations which require constant muscular activity also limits the possibility of greatly extending the working period.

With units of so greatly different value the efficiency expert quickly reaches the conclusion that the units whose time is of less value (i.e. the school children) should be brought in touch with the units of greater value (i.e. the dentist). The cost of tranporting the children to a central situation (10 cents for carfare) and the cost of their oversight (time of school nurses) does not appreciably modify the relative value of the units.

Unlike the physician the dentist requires a complex equipment in order that he may work. The multiplication of dental outfits in many situations necessitates the duplication of many parts of the plant outside of the chair and instruments.

Dentistry is surgery and no form of professional activity offers more opportunities for the transmission of disease from one individual to another so that rigid asepsis is an essential. A central plant where the sterilization of everything which enters the mouth is under the control of an individual whose sole business this is, surely furnishes a more complete check on cross infection than the divided effort in small plants.

\section{THE VOLUNTEER DENTIST.}

The physician who gives two or three hours per day to a public charity feels the income loss slightly if at all since he has a large part of the day to recoup the lost time. The busy dentist who gives of his daylight hours to a charity must take from this a definite loss of income which cannot be made up. Those who have had practical experience in the establishment and oversight of volunteer dental clinics can best appreciate the difficulty of obtaining volunteers among experienced men.

Success in dentistry is associated with more and more exacting demands on the time of the dentist who increases his income not by increasing the length of his working day, but by de- 


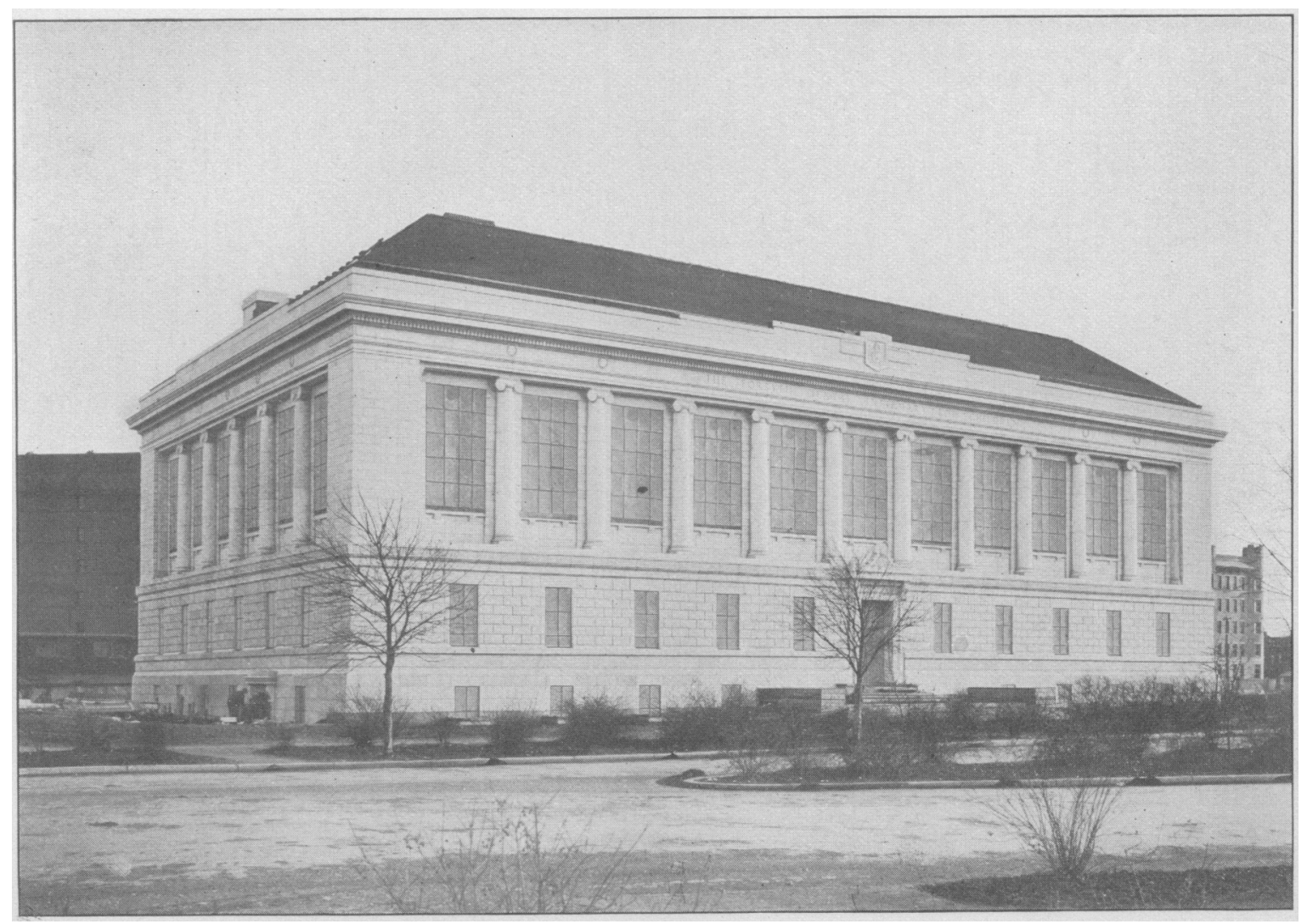

FORSYTH DENTAL INFIRMARY FOR CHILDREN 
manding a larger sum per hour for his services. Success in medicine is often associated with less exacting demands on the time of the physician as a practice is converted into a consulting practice.

The eminent physician who gives his time to a public charity is required to do a minimal amount of routine work and is rewarded by the legitimate advertising arising from his connection with a hospital and also by the opportunity to add to his experience by the concentration of a large amount of clinical material in the institution. This material also makes it possible for him to add to his reputation by teaching. In other words, public service attracts the most eminent members of the medical profession by the opportunities which it creates.

It is our belief that public dental service should in a similar way offer opportunities which will attract to it the most eminent members of the dental profession as well as the rank and file.

The Forsyth Dental Infirmary for Children was founded as a memorial to James Bennett Forsyth and George Henry Forsyth. Its first group of trustees was made up of leading educators and professional men together with three representatives of the dental profession. The most active member of this group was Dr. Edward W. Branigan who had given the greater part of his life to dental education and notably to the problem of the care of children's teeth. The death of Dr. Branigan and the resignation of other members led to a reorganization of the board which as now constituted is made up of four business men, two physicians, and four dentists - one representing the Baltimore dental schools, one representing the Philadelphia dental schools, and one representing each of the local dental schools, under the presidency of Thomas Alexander Forsyth, one of the donors.

This institution is dedicated to the children. It is the purpose of the foundation to care for mouth conditions in worthy children under the age of sixteen years. Its functions will include not only the care of the teeth but also related oral diseases including defective palates, adenoids, etc. Much of the work it will be called upon to do in its early years will deal with the curing of already established processes. - When established processes are under control it is expected that it will have to do in great part with the prevention of defects by oral prophylaxis. The building which will house the foundation is under construction on the Fenway. It is intended as a memorial to the dead Forsyth brothers and is fittingly monumental in character. When completed it is the consensus of opinion that it will be one of the most ornamental structures in the city. The trustees for the past two years have bent all of their efforts to make its appointments so complete that its equipment will be adequate for the Herculean task which this new work will entail.

Nowhere in the world up to this time has an attempt been made to care for the dental requirements of the children of a great city. Small clinics have been established in manv cities, but nothing on a similar scale is in existence in the world. Many new problems have had to be met since the character of the institution has necessitated the creation of agencies hitherto uncalled for. The Board of Trustees has met many of the old problems as though they were new ones, and the equipment of the institution will be marked by many changes from standard devices. The main problem has been the question of supplying expert dentists for carrying on the details of the work. This problem we believe we have solved by adopting the methods demonstrated to be successful in public medical institutions. The foundation of successful work in hospitals dealing with acute conditions is the house officer. $\mathrm{He}$ is a recent graduate in medicine who gladly gives his time to the institution in return for the experience gained. The clinics of the dental schools try to supply a similar demand in dentistry but not always adequately. Post-graduate training in dentistry is rarely obtained except through opportunity to assist dentists in their offices. The average dental student goes directly from the dental school into the practice of his profession.

The generous endowment of the Forsyth Dental Infirmary outside of the cost of the building will permit of the employment of recent graduates in dentistry at a small salary. On completion of a satisfactory service of one or two years each of these members of the permanent staff will be given a diploma certifying his service. It is believed that this service with its opportunities for wide experience will attract picked men from the dental graduates of the whole country and further will train a group of experts on oral prophylaxis whose influence on the profession will be widespread. The number of dentists whose whole time can be paid for in this will be necessarily limited. Among recent graduates who are practising in this city are many, however, whose time is not wholly occupied by their practices and who would be willing to give half time to the institution for a small remuneration. They, with the whole-time men, will constitute the permanent staff.

A volunteer staff will be made up of dentists who are willing to give one-half day per week or per two weeks or per month to charity. In order to draw to this service the eminent members of the local profession it is intended to make the institution a clearing house for the newer things in dentistry. Here will be concentrated an enormous amount of clinical material. It is our purpose to invite experts who are dealing with dental problems in any part of the world to come to Boston and report the results of their experience. Clinics will be held by experts in the various branches of dentistry and the busy local practitioner will be kept in touch with dental progress. In other words he will be given the opportunity which the general practitioner in 
medicine seeks when he takes post-graduate instruction or which the visiting physician to a hospital obtains as the result of his connection with the institution. It is recognized in medicine that those public hospitals do the best work for their patients in which clinical teaching is practiced. The members of the visiting staff of such an institution are compelled to keep in touch with modern progress or be subjected to the criticism of students. Their patients profit by the mental acuteness which such a training develops. The value of such continuous instruction to the dental profession of Boston cannot be overestimated. Its value in turn to the children who come under their care should be a tangible asset to the community.

Men who would be unwilling to devote time to the deadly routine of a one or two-chair clinic should find in this central clinic with its perfect facilities and large clientele so potent an attraction that the difficulties which the small clinies are suffering in obtaining volunteers should not be met.

The research department of the institution is supported by a fund set aside from the rest ofthe endowment and should add materially to the World's knowledge of dental conditions.

From the practical standpoint the following figures may of value. The institution will start with an equipment of 64 chairs which may be increased to 106 as needs demand. It is estimated that each chair will care for 12 patients in an eight-hour day. This allows for more than a single filling if necessary. Seven hundred and sixty-eight patients per day can be treated with the initial equipment according to this schedule. With 300 working days per year 230,400 operations can be carried out. This will allow for three treatments annually of 76,800 children. With full equipment 381,600 operations can be carried out or three treatments annually of 127 ,200 children. In considering these figures it should be remembered that a large percentage of school children will be cared for, as now in dental offices, at the expense of their parents.

It would seem that schemes for school or local dental clinies at the expense of the taxpayers of Boston should be held in abeyance until this splendid charity dedicated to the children has had an opportunity to demonstrate whether it will be adequate to cope with the dental needs of the school children or not.

This foundation seeks the good will of the sister professions, medicine and dentistry, and looks for their co-operation in its effort to uplift the physical standard of humanity.

A WORD ON THE SCIENTIFIC, ECONOMIC, AND SOCIAL PROGRAM OF THE FORSYTH DENTAL INFIRMARY.

BY HAROLD DE WITT CROSS, D.M.D.

Dr. Leary has told you how the Forsyth Dental Infirmary for Children came into existerice, and I will tell you a little about the building and its work. It is very appropriate that this subject should be discussed before a medical society because the medical and the dental men are equally interested in it. The subject has incited much interest not only in this vicinity, but in all portions of this country and all over the world. There are many problems to meet in undertaking the establishment of an institution of this kind, problems in connection with the building, its equipment, and the selection and organization of the staff.

This is the day of endowments. Schools, hospitals and clinics are being endowed, and established in many places; but there is none which compares with the Forsyth Infirmary, in the magnitude of its undertaking, and it is all for the children. The exterior of the building is monumental, because it is to serve as a memorial as well as an infirmary. The interior will be constructed with regard to the most improved style of hospital finish. The chairs are to be made without corners and with a smooth metalic surface which can be easily cleaned and sterilized. The instruments arranged in sets, suitable for all ordinary operations, will be placed in suitable metal trays, which, together with the enclosed instruments will be cleaned and sterilized, and a complete, sterile set provided to be used with each patient.

The lavatories are to be of the hospital operating-room type, somewhat modified, and will be provided-with an aseptic soap server of new design. The improvements which have been made in the lavatories will no doubt establish a new standard for aseptic fixtures.

The principal rooms of the building are as follows: The infirmary, the main room of the building, is a large, airy, light room and will be equipped with modern dental apparatus for all operations, extracting, orthodontia, "surgical and research rooms, a children's waiting room, a permanent and a visiting staff's, a nurses' and a students' room, and a large lecture hall.

The entire staff is to be composed of a consulting, visiting and a permanent force. The visiting staff's services will be gratuitous, but the permanent staff will receive a moderate compensation, and those serving on it will devote their entire time to the work. It is quite possible that a competitive examination may be necessary to obtain a place on the staff. These positions will be filled by recently graduated men, who will find the experience invaluable, and the training will in many ways be the equivalent of a postgraduate course.

The research laboratory will be completely equipped with suitable apparatus, and in it will be an experienced person devoting his entire time to research work. It is to be hoped that many problems, now unknown, will be solved in connection with the diseases of the oral cavity.

The museum will be a repository of pathological specimens and will serve as a centre for the dissemination of knowledge of oral hygiene. 